\title{
DOUBLE BLIND CONTROLLED STUDY OF ADDING FOLIC ACID TO FLUOXETINE IN THE TREATMENT OF OCD
}

\author{
Ümit Tural ${ }^{1}$, Aytül Çorapçığlu ${ }^{2}$, Şükriye Boşgelmez ${ }^{2}$, Gültürk Köroğlu ${ }^{2}$, Hatice Ünver ${ }^{3}$, \\ Can Duman ${ }^{4} \&$ Emin Önder ${ }^{2}$ \\ ${ }^{I}$ Department of Psychiatry, The Nathan S. Kline Psychiatric Research Institute, Orangeburg, New York, USA \\ ${ }^{2}$ Department of Psychiatry, Medical Faculty at the University of Kocaeli, Umuttepe Kocaeli, Turkey \\ ${ }^{3}$ Department of Child and Adolescent Psychiatry, Medical Faculty at the University of Marmara, Istanbul, Turkey \\ ${ }^{4}$ Department of Biochemistry, Medical Faculty at the University of Kocaeli, Umuttepe, Kocaeli, Turkey
}

received: 17.8.2018;

revised: 3.11.2018;

accepted: 29.11 .2018

\begin{abstract}
SUMMARY
Background: Folate is important for the synthesis of serotonin the neurotransmitter which plays a main role in OCD. We, therefore, explored the efficacy of folic acid as add on treatment to fluoxetine in a double blind study among patients with OCD.

Subjects and methods: A double blind, 12-week study comparing the efficacy of folic acid as add on treatment and placebo in patients with OCD was conducted on thirty six (36) patients. Patients were randomly assigned to folic acid (5 mg/day) or placebo group in addition to fluoxetine (40 mg/day). After the baseline assessment, on week 2, 4, 6, 8 and 12 assessments were performed by using YBOCS, HAM-D, HAM-A and CGI-S. Serum folate, erythrocyte folate, serum homocysteine and $B_{12}$ levels were measured both baseline and the end of study.

Results: A mixed model repeated measures ANCOVA on Y-BOCS scores were used to determine the difference between folic acid and placebo groups. No significant differences were found in the ratios of gender or in the mean age, serum folic acid level, erythrocyte folate level, serum homocysteine level and serum $B_{12}$ level between the treatment groups at the baseline. Consecutively scores collected over six measurements on YBOCS, HAM-D, HAM-A and CGI showed non-significant differences between folic acid and placebo groups.
\end{abstract}

Conclusion: None of the biological markers of one carbon metabolism were associated with the change in YBOCS scores. It may be assumed that there is no beneficial effect of folic acid addition to fluoxetine in the treatment of OCD.

Key words: $O C D$ - fluoxetine - serum folate - red cell folate - serum homocysteine - vitamin $B_{12}$

$$
* * * * *
$$

\section{INTRODUCTION}

Low levels of folate and vitamin $\mathrm{B}_{12}$ have been associated with low levels of serotonin metabolite 5-hydroxyindolacetic acid (5-HIAA) in cerebrospinal fluid in humans as well as in rats (Botez et al. 1979, Botez et al. 1982). Furthermore, low to deficient levels of folate in serum and erythrocytes have been associated with depressive disorders, greater severity of depression, low or delayed response rate to antidepressants, and increased relapse rates (Abou-Saleh et al. 1986, Carney et al. 1990, Fava et al. 1997, Abou- Saleh \& Coppen 1989, Bottiglieri et al. 1992, Bottiglieri et al. 2000, Coppen et al. 1989, Coppen \& Bailey 2000, Papakostas et al. 2005, Papakostas et al. 2004, Papakostas et al. 2004, Tolmunen et al. 2004, Wilkinson et al. 1994). Studies have been suggesting that folic acid and its derivates can be used in the treatment of depression as add-on treatment (Coppen \& Bailey 2000, Guaraldi et al. 1993, Di Palma et al. 1994, Alpert et al. 2002). Previously, it was shown that methyfolate (5-methyltetrahydrofolate- MTHF), a derivate of folate which is actively transportted into central nervous system-CNS) significantly improved the outcome of depressed patients with definite or just borderline folate deficiency after addition of -to standard psychotropic treatment in a double-blind, placebo-con- trolled study (Godfrey et al. 1990). Coppen \& Bailey (2000) demonstrated that the co-administration of folic acid substantially and significantly improve the response to fluoxetine in female depressed patients but not in male. Papakostas and colleagues found a relationship between serum folate level and the timing of improvement with fluoxetine, resistance to medication, and relapse during the continuation phase of pharmacotherapy (Papakostas et al. 2005, Papakostas et al. 2004, Papakostas et al. 2004).

Folate appears to influence the rate of synthesis of tetrahydrobiopterin, the cofactor in the hydroxylation of phenylalanine and tryptophan (Coppen et al. 1989, Bottiglieri \& Hayland 1994, Hamon et al. 1986). Because this is the rate limiting step in the biosynthesis of dopamine, norepinephrine and serotonin, alterations in the rate of synthesis of this important cofactor may be relevant to depression or other psychiatric disorders such as obsessive compulsive disorder (OCD). It has hypothesized that OCD may be associated with serotoninergic dysfunction, and the clinical effects of selective serotonin reuptake inhibitors (SSRIs) may suggest an indirect role of serotonin in obsessions and compulsions (Lee et al. 2018, Sinopoli et al. 2017, Van Praag 1982, Westenberg et al. 2007). Methyltetrahydrofolate has been shown to bind to presynaptic glutamate receptors, 
where it may bind to presynaptic glutamate receptors, potentially modulate the release of other neurotransmitters including the monoamines (Ruck et al. 1980). Furthermore, glutamatergic system may be involved in the neurochemical disturbances existing in OCD (Baxter 2001, Coric et al. 2005).

Clinical interventions commonly used for the treatment of OCD provide symptom improvement in about $40-60 \%$ of patients with OCD; however, there are a considerable number of patients in whom enough symptom reduction $(20-40 \%)$ can not be obtained that indicate a need for the new pharmacological treatment options (Jenike 2004). Although, folate and $\mathrm{B}_{12}$ deficiencies and disturbance of one-carbon metabolism or use of folate and its derivates as an antidepressant or augmentation with folic acid of antidepressant drug action are well studied in depression, such studies have not been done in OCD yet. There are a few studies of serum folate levels in patients with OCD. In a study, the authors indicated that serum $\mathrm{B}_{12}$ levels were significantly associated with OCD whereas folate levels did not with OCD and other psychiatric disorders (Hermes et al. 1988). A more recent study found both lowered blood level of folate and increased blood level of homocysteine in comparison to healthy controls, and both folate and homocysteine were significantly correlated with symptom severity of OCD as assessed with Yale-Brown Obsessive Compulsive Scale (YBOCS) total score (Atmaca et al. 2005). Taken together that strong evidence of benefits of folate in the treatment of depression and results from a few studies suggesting a possibility of impaired one carbon metabolism in OCD, a study of serum homocysteine, $\mathrm{B}_{12}$, folate, and erythrocyte folate concentrations in patients with OCD and whether the co-administration of folic acid would augment the anti obsessive-compulsive action of fluoxetine has been undertaken.

\section{SUBJECTS AND METHODS}

\section{Participants}

A randomized, double-blind parallel group, placebo controlled trial completed in outpatient psychiatry clinic of Kocaeli University. The participants and clinicians were blinded to interventions after assignment. Forty patients with Diagnostic and Statistical Manual of Mental Disorders, $4^{\text {th }}$ Edition, Text Revision (DSM-IVTR) diagnosis of OCD were randomly assigned to receive either a tablet of $5 \mathrm{mg}$ folic acid or an identical looking placebo tablet to take with their fluoxetine. Computer based randomization procedure was used. All patients were prescribed $20 \mathrm{mg}$ of fluoxetine as starting dose. After the first week of fluoxetine treatment, the dosage of fluoxetine optimized to $40 \mathrm{mg}$ daily. No further effort was made to balance the samples, for example according to gender or duration and severity of OCD, during randomization process. The medication adherence and patient compliance were assessed through checking with the patient and his/her caregiver along with a pill count at each visit. Patients were excluded from study entry for the following reasons: having a total score on the 17-item Hamilton Depression Rating Scale (HAM-D) of 12 or higher score, being a woman who was currently pregnant or lactating, being diagnosed with cerebrovascular disease, Parkinson's Disease, Alzheimer's Disease, having a current or past diagnosis of schizophrenia, other psychotic disorders, manic or hypomanic episode verified with medical records, diagnosed with recurrent depression, known poor or non-response to previous treatment with fluoxetine, having a DSM-IV-TR defined diagnosis of alcohol or substance abuse and/or dependence in the past 6 months, having a clinically relevant abnormal laboratory test including megaloblastic anemia, having an unstable or severe physical illness, current ingestion of drugs known to affect homocysteine, $\mathrm{B}_{12}$, and folate levels (e.g. antiepileptic, lithium), receiving treatment with a depot neuroleptic within 1 month. Concomitantly using any psychotropic medication was not permitted other than alprazolam for sleep if needed. All previous psychotropic medications had been withdrawn for at least 1 week before sampling. After informed patient consent, baseline fasting blood samples were obtained in all patients for examination of full blood count, liver function tests, routine urine tests, thyroid tests (TSH, $\mathrm{T}_{3}$, $\mathrm{T}_{4}$ ), serum and red blood cell folate, serum $\mathrm{B}_{12}$, and total serum homocysteine. No dietary restrictions were imposed. At the endpoint (week 12), fasting serum homocysteine, $\mathrm{B}_{12}$, folate and $\mathrm{RBC}$ folate levels were reevaluated. At each follow up appointment, the patient was questioned about any possible adverse effects of the medication. The study was approved by the local ethics committee and registered (143-6/116).

\section{Scales}

All patients entering the study were rated on the clinical rating scales, the 17-item Hamilton Depression Rating Scale (HAM-D), Hamilton Anxiety Scale (HAMA), Yale-Brown Obsessive Compulsive Scale (YBOCS), Clinical Global Impression-Severity of Illness (CGI-S). Psychometric assessments were performed at baseline, weeks $2,4,6,8$, and 12 by using all of the mentioned scales. We explored and compared the "response" rates between the placebo and folic acid group. A response was defined as $30 \%$ or more drop in the end point YBOCS total score as compared with baseline.

Yale Brown Obsession Compulsion Scale was developed to detect the character and severity of obsessivecompulsive symptoms, and consists of two parts (Goodman et al. 1989). Questions 1-5 evaluate severity of obsessions; questions 6-10 evaluate severity of compulsions. Validity and reliability in Turkish was made (Karamustafalığlu et al. 1993).

The Hamilton Anxiety Rating Scale (HAM-A) is a 14-item questionnaire to be rated by the clinician, assessing severity of generalized anxiety (Hamilton 
1969). The validity and reliability of Turkish version was confirmed (Yazıc1 et al. 1998).

Hamilton Depression Rating Scale was designed as a tool to measure the severity of illness inpatients diagnosed with depression (Hamilton 1967). The version of the instrument utilized in the study contains 17 items. According to the options chosen by rater, each item contributes a score of $0,1,2,3$, or 4 points toward a HAM-D total. A 17-item HAM-D total score may theoretically range from 0 to 52 . Its validity and reliability for use with the Turkish population was done (Akdemir et al. 2001).

The Clinical Global Impression was developed and published by National Institute of Mental Health in 1976, a brief instrument, comprising of two parts, the first being a clinician's rating of the severity of the disease (CGI-S), and the second for assessing general improvement or deterioration, and side effects of the drugs (Guy 1976). In this study, we used the first part that the severity of psychiatric symptoms was clinically assessed by means of CGI-S that gives a score ranging from 1 (disease free) to 7 (greatest severity possible).

\section{Biologic Assays}

The blood samples were taken from antecubital vein between 9 and 11 AM after an overnight fast. Serum folate, erythrocyte folate and serum $B_{12}$ levels were measured using ECLIA (Roche Diagnostics Elecsys 2010 immune analyzer). Normal range for serum cobalamin was $197-866 \mathrm{pg} / \mathrm{ml}(145-637 \mathrm{pmol} / \mathrm{L})$; for serum folate was $3.1-17.5 \mathrm{ng} / \mathrm{ml}(7.0-39.7 \mathrm{nmol} / \mathrm{L})$; for erythrocyte folate was $176-589 \mathrm{ng} / \mathrm{ml}(401-1338 \mathrm{nmol} / \mathrm{L})$ as established by the kit manufacturer. Plasma total Lhomocysteine estimation was carried out using FPIA in the IMx system (Abbott Diagnostic, Abbott Park, IL, USA). Normal range for plasma total L-homocysteine was $4.45-12.42 \mu \mathrm{mol} / \mathrm{L}$ as established by the kit manufacturer. In the present study we analyzed the results according to the standard lower limits of the normal range as suggested by the kit manufacturer, namely $197 \mathrm{pg} / \mathrm{ml}$ for cobalamin, $3.1 \mathrm{ng} / \mathrm{ml}$ for serum folate, and $176 \mathrm{ng} / \mathrm{ml}$ for erythrocyte folate. All results below these values were considered to be lower than normal. If the value of plasma totals homocysteine values higher than $12.42 \mu \mathrm{mol} / \mathrm{L}$, it was accepted as higher than normal.

\section{Statistical analysis}

Sociodemographic variables were assessed either with independent samples t-test for continuous variables or Chi square test for categorical variables. Yates' corrected chi-square or Fisher's exact test were used when appropriate. Pearson or partial correlations were used to explore the relationship between interested variables and the biochemical markers, MANOVA was used for comparing. Multivariate sample means between the placebo and folic acid groups. If significant difference was found by multivariate $\mathrm{F}$ test, then follow up univariate ANOVAs with Bonferroni adjustment for type I error were performed. In the main analysis, the outcome (dependent) measure was observed changes in the total score of YBOCS, which had been collected over six measurements, between the two treatment arms. Because of gender differences, may have an effect on the antidepressant responses (Coppen and Bailey, 2000, Martenyi et al. 2001) gender was added as a second "between-subjects factor" to the mixed model repeated measures of ANOVA to test the main hypothesis which allows us to evaluate both inclusive and exclusive of the effects of gender. Preliminary assumption testing for ANOVAs was conducted. All analyses were based on the ITT patient sample. The significance level was always set at 0.05 (two sided). Partial Eta Square $\left(\mathrm{eta}_{\mathrm{p}}{ }^{2}\right.$ ) was reported as an indicator of effect size for ANOVAs.

\section{RESULTS}

\section{Sample}

Fifty eight patients were screened. Forty three patients with OCD were enrolled; however, seven patients dropped out the study because of refusal to give a blood sample at the time of venipuncture (2 patients) or incomplete baseline psychiatric assessments (4 patients) or violate the study agreement (1 patient). Therefore, remaining 36 patients were included in further statistical analyses. The mean age of the whole group was $32.6 \pm 10.9$ years. There was no significant difference between the ages of the two treatment groups (Table 1) or between the mean ages of men $(n=14,32.16 \pm 11.41$ yrs $)$ and women $(n=22,31.86 \pm 10.71$ yrs; $t=-0.265$, $\mathrm{df}=34, \mathrm{P}=0.793$ ). Gender distribution was not significantly different between the treatment groups. None of the baseline psychometric or biochemical parameters was significantly different between the treatment groups (Table 1). The comorbidities in OCD group were as follows: four patients with panic disorder, 2 patients with social phobia, 1 patient with generalized anxiety disorder, 1 patient with post-traumatic stress disorder.

\section{Adverse effects}

Twelve out of 18 patients $(66.7 \%)$ reported adverse effects of the treatment in fluoxetine plus placebo group; 6 patients reported a mild increase of anxiety symptoms, 5 of headache, 2 of nausea, and 3 of insomnia. Fifteen patients $(83.3 \%)$ reported adverse effects of the treatment in fluoxetine+folic acid group; 5 patients suffered from nausea, 4 from difficulty concentrating, 4 from flatulence, 2 from gastrointestinal discomfort, 2 from reddened skin. Total adverse effects frequency was not significantly different between the groups $\left(\chi^{2}=0.593, \mathrm{df}=1, \mathrm{P}=0.441\right)$. Five $(13.9 \%)$ of subjects withdrew from the study during follow up period due to adverse effects ( 2 in $\mathrm{flx}+$ placebo, 3 in flx + folic acid group). 
Table 1. Baseline Comparisons between the Groups

\begin{tabular}{|c|c|c|c|}
\hline & Flx Alone Group & Flx + Folic Acid Group & Statistic and $P$ value \\
\hline Age $($ Mean \pm SD $)$ & $33.44 \pm 11.62$ & $31.06 \pm 10.18$ & $\mathrm{t}=0.656, \mathrm{df}=34, \mathrm{p}=0.516$ \\
\hline Gender (Female n, \%) & $12(66.7 \%)$ & $10(55.6 \%)$ & $\chi^{2}=0.117, \mathrm{df}=1, \mathrm{p}=0.732$ \\
\hline HAM-D Score $($ Mean \pm SD) & $6.06 \pm 3.08$ & $6.17 \pm 2.73$ & $\mathrm{t}=-0.115, \mathrm{df}=34, \mathrm{p}=0.909$ \\
\hline HAM-A Score $($ Mean \pm SD) & $16.22 \pm 9.15$ & $17.56 \pm 9.91$ & $\mathrm{t}=-0.419, \mathrm{df}=34, \mathrm{p}=0.678$ \\
\hline Y-BOCS Score (Mean \pm SD) & $24.78 \pm 8.41$ & $27.89 \pm 5.97$ & $\mathrm{t}=1.280, \mathrm{df}=34, \mathrm{p}=0.209$ \\
\hline CGI-S (Mean \pm SD) & $4.44 \pm 1.25$ & $4.94 \pm 0.873$ & $\mathrm{t}=-1.394, \mathrm{df}=34, \mathrm{p}=0.172$ \\
\hline Serum folate, $\mathrm{ng} / \mathrm{ml}(\mathrm{Mean} \pm \mathrm{SD})$ & $8.13 \pm 3.19$ & $6.63 \pm 1.98$ & \\
\hline Erythrocyte folate, ng/ml (Mean \pm SD) & $449.13 \pm 94.30$ & $461.11 \pm 231.90$ & Pillai's trace: $\mathrm{F}_{(4,31)}=1.047$, \\
\hline Serum homocysteine, $\mu$ mol/L(Mean \pm SD) & $12.35 \pm 3.26$ & $15.21 \pm 9.09$ & \\
\hline Serum $B_{12}, \mathrm{pg} / \mathrm{ml}($ Mean $\pm \mathrm{SD})$ & $286.99 \pm 132.36$ & $232.12 \pm 69.20$ & \\
\hline
\end{tabular}

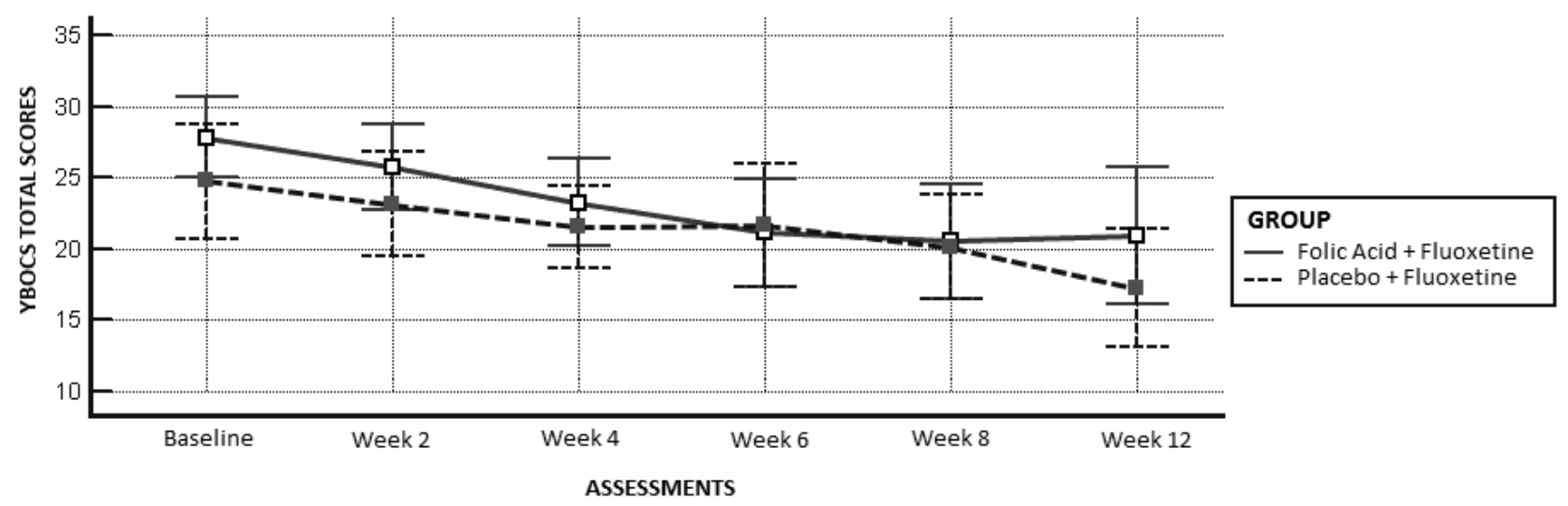

Figure 1. Changes in YBOCS total scores (error bars: 95\% CI for mean)

\section{Serum Folate, $B_{12}$, Homocysteine, and RBC folate levels at baseline}

All of 36 patients' serum folate levels were within the normal range. However, 4 (11.1\%) patients' erythrocyte folate levels were low, and 7 (19.4\%) patients' serum $\mathrm{B}_{12}$ levels were low according to the reference intervals. Twenty one $(58.3 \%)$ patients' serum total homocysteine levels were higher than upper limits. One way between groups MANOVA was performed to investigate the treatment group (placebo vs. folic acid) differences in biochemical markers' serum levels at baseline. We found no baseline significant differences between the groups by means of biochemical parameters associated with one carbon system (Table 1). There were no significant correlation between age and baseline serum folate $(\mathrm{r}=0.082$, $\mathrm{P}=0.636)$, homocysteine $(\mathrm{r}=0.184, \mathrm{P}=0.281), \quad \mathrm{B}_{12}$ $(\mathrm{r}=-0.024, \mathrm{P}=0.891)$, and $\mathrm{RBC}$ folate levels $(\mathrm{r}=-0.144$, $\mathrm{P}=0.401)$. Mean serum folate, erythrocyte folate, homocysteine and $\mathrm{B}_{12}$ levels were not significantly different between men and women $\left(\mathrm{F}_{(4,31)}=2.278, \mathrm{P}=0.083\right.$, $\left.\mathrm{eta}_{\mathrm{p}}{ }^{2}=0.227\right)$.

\section{Correlation between baseline YBOCS scores and Serum Folate, $B_{12}$, Homocysteine, and RBC folate levels}

Partial correlation was used to explore the relationship between Y-BOCS total score and the interested biochemical marker, while controlling for the levels of other biochemical markers. There was a medium and negative correlation between blood level of $\mathrm{B}_{12}$ and $\mathrm{Y}$ BOCS total score $(r=-0.396, n=31, P=0.022)$. However, there were no significant correlations between $\mathrm{Y}$-BOCS total score and serum folate $(\mathrm{r}=-0.066, \mathrm{n}=31, \mathrm{P}=0.714)$, homocysteine $(\mathrm{r}=-0.085, \mathrm{n}=31, \mathrm{P}=0.639)$, and erythrocyte folate level $(\mathrm{r}=-0.127, \mathrm{n}=31, \mathrm{P}=0.482)$.

\section{Effect of the treatment on OCD severity}

A mixed model repeated measures ANOVA approach showed that there was a significant change in YBOCS total scores collected over six assessments $\left(\mathrm{F}_{(5,28)}=7.683, \mathrm{P}<0.0005, \mathrm{eta}_{\mathrm{p}}{ }^{2}=0.578\right)$ in whole sample with a medium effect size (Figure 1). However, there was no significant effect of time by treatment interaction $\left(\mathrm{F}_{(5,28)}=1.848, \mathrm{P}=0.136\right.$, eta $\left.{ }_{\mathrm{p}}{ }^{2}=0.248\right)$, time by gender interaction $\left(\mathrm{F}_{(5,28)}=1.408, \mathrm{P}=0.252\right.$, eta $\left._{\mathrm{p}}{ }^{2}=0.201\right)$, and time by treatment by gender interaction $\left(\mathrm{F}_{(5,28)}=1.066, \mathrm{P}=0.400\right.$, eta $\left.{ }_{\mathrm{p}}{ }^{2}=0.160\right)$. Then, repeated measures ANCOVA showed that change across the study $(\Delta)$ in the biochemical markers' levels ( $\Delta$ folate $\mathrm{F}_{(5,27)}=0.967, \mathrm{P}=0.455$, eta $_{\mathrm{p}}{ }^{2}=0.152 ; \Delta$ erythrocyte folate $\mathrm{F}_{(5,27)}=0.148, \quad \mathrm{P}=0.979, \quad$ eta $_{\mathrm{p}}{ }^{2}=0.027 ; \quad \Delta$ homocysteine $\mathrm{F}_{(5,27)}=0.732, \mathrm{P}=0.605$, eta ${ }_{\mathrm{p}}{ }^{2}=0.119 ; \Delta \mathrm{B}_{12} \mathrm{~F}_{(5,27)}=0.293$, $\mathrm{P}=0.912$, eta ${ }_{\mathrm{p}}{ }^{2}=0.052$ ) were not significantly associated with changes in YBOCS scores collected repeatedly six measurements. There were no significant time by treatment interaction in obsession $\left(\mathrm{F}_{(5,160)}=1.124\right.$, $\mathrm{P}=0.350$, eta $\left.{ }_{\mathrm{p}}{ }^{2}=0.034\right)$ or compulsion $\left(\mathrm{F}_{(5,160)}=1.261\right.$, $\mathrm{P}=0.283$, eta $_{\mathrm{p}}{ }^{2}=0.038$ ) subscales of YBOCS. 
Table 2. Effect of the treatment on biochemical parameters*

\begin{tabular}{|c|c|c|c|c|c|}
\hline \multirow{2}{*}{ Variable } & \multirow{2}{*}{$\begin{array}{l}\text { Treatment } \\
\text { Group }\end{array}$} & \multirow{2}{*}{$\begin{array}{c}\text { Baseline } \\
(\text { Mean } \pm \text { SD })\end{array}$} & \multirow{2}{*}{$\begin{array}{c}\text { Endpoint } \\
(\text { Mean } \pm \text { SD) }\end{array}$} & \multicolumn{2}{|c|}{ Comparisons } \\
\hline & & & & Within Groups & Between Groups \\
\hline \multirow[t]{2}{*}{$\begin{array}{l}\text { Serum folate } \\
(\mathrm{ng} / \mathrm{ml})\end{array}$} & Placebo & $8.13 \pm 3.19$ & $8.04 \pm 3.08$ & $\begin{array}{c}\mathrm{F}_{(1,17)}=0.47, \mathrm{p}=0.832, \\
\text { eta }^{2}=0.003\end{array}$ & \multirow{2}{*}{$\begin{array}{c}\mathrm{F}_{(1,34)}=75.962, \\
\mathrm{p}<0.0005, \text { eta }^{2}=0.691\end{array}$} \\
\hline & Folic acid & $6.63 \pm 1.98$ & $30.22 \pm 10.99$ & $\begin{array}{c}\mathrm{F}_{(1,17)}=77.506, \\
\mathrm{p}<0.0005, \mathrm{eta}^{2}=0.820\end{array}$ & \\
\hline \multirow[t]{2}{*}{$\begin{array}{l}\text { Erythrocyte folate } \\
(\mathrm{ng} / \mathrm{ml})\end{array}$} & Placebo & $449.13 \pm 94.30$ & $476.15 \pm 114.67$ & $\begin{array}{c}\mathrm{F}_{(1,17)}=1.182, \\
\mathrm{p}=0.292, \mathrm{eta}^{2}=0.065\end{array}$ & \multirow{2}{*}{$\begin{array}{c}\mathrm{F}_{(1,34)}=36.137, \\
\mathrm{p}<0.0005, \mathrm{eta}^{2}=0.515\end{array}$} \\
\hline & Folic acid & $461.11 \pm 231.90$ & $936.80 \pm 224.85$ & $\begin{array}{c}\mathrm{F}_{(1,17)}=45.685, \\
\mathrm{p}<0.0005, \text { eta }^{2}=0.729\end{array}$ & \\
\hline \multirow[t]{2}{*}{$\begin{array}{l}\text { Serum homocysteine } \\
(\mu \mathrm{mol} / \mathrm{L})\end{array}$} & Placebo & $12.35 \pm 3.26$ & $12.18 \pm 2.00$ & $\begin{array}{c}\mathrm{F}_{(1,17)}=0.30, \mathrm{p}=0.864 \\
\text { eta }^{2}=0.002\end{array}$ & \multirow{2}{*}{$\begin{array}{c}\mathrm{F}_{(1,34)}=4.115, \mathrm{p}=0.050, \\
\text { eta }^{2}=0.108\end{array}$} \\
\hline & Folic acid & $15.21 \pm 9.09$ & $10.00 \pm 2.63$ & $\begin{array}{c}\mathrm{F}_{(1,17)}=5.203, \mathrm{p}=0.036 \\
\text { eta }^{2}=0.234\end{array}$ & \\
\hline \multirow[t]{2}{*}{$\begin{array}{l}\text { Serum } B_{12} \\
(\mathrm{pg} / \mathrm{ml})\end{array}$} & Placebo & $286.99 \pm 132.36$ & $289.25 \pm 116.07$ & $\begin{array}{c}\mathrm{F}_{(1,17)}=0.122, \mathrm{p}=0.731, \\
\text { eta }^{2}=0.007\end{array}$ & \multirow{2}{*}{$\begin{array}{c}\mathrm{F}_{(1,34)}=0.108, \mathrm{p}=0.745, \\
\text { eta }^{2}=0.003\end{array}$} \\
\hline & Folic acid & $232.12 \pm 69.20$ & $231.91 \pm 63.46$ & $\begin{array}{c}\mathrm{F}_{(1,17)}=0.003, \mathrm{p}=0.957 \\
\text { eta }^{2}<0.0005\end{array}$ & \\
\hline
\end{tabular}

* Global MANOVA, Pillai's trace: $\mathrm{F}_{(4,31)}=19.382, \mathrm{p}<0.0005$, eta ${ }^{2}=0.714$

Table 3. Effect of the treatment on psychometric measures

\begin{tabular}{llccccccc}
\hline & & Baseline & Week 2 & Week 4 & Week 6 & Week 8 & Week 12 & Statistic \\
\hline YBOCS & Placebo & $24.78 \pm 8.41$ & $23.17 \pm 7.55$ & $21.56 \pm 6.04$ & $21.67 \pm 8.90$ & $20.17 \pm 7.57$ & $17.28 \pm 8.64$ & $\begin{array}{c}\text { Pillai's trace: } \\
\end{array}$ \\
& Folic acid & $27.89 \pm 5.97$ & $25.78 \pm 6.25$ & $23.28 \pm 6.31$ & $21.17 \pm 7.82$ & $20.56 \pm 8.35$ & $20.94 \pm 10.03$ & $\begin{array}{c}\text { F }(5,28)=1.848, \mathrm{p}=0.136, \\
\text { eta }^{2}=0.248\end{array}$ \\
HAM-D & Placebo & $6.06 \pm 3.08$ & $6.22 \pm 3.15$ & $6.17 \pm 3.185$ & $5.72 \pm 3.39$ & $5.56 \pm 3.45$ & $5.50 \pm 3.03$ & $\begin{array}{c}\text { Pillai's trace: } \\
\text { HAM-A }\end{array}$ \\
& Folic acid & $6.17 \pm 2.73$ & $6.72 \pm 2.85$ & $6.50 \pm 3.204$ & $6.11 \pm 3.05$ & $5.72 \pm 3.72$ & $5.78 \pm 3.54$ & $\mathrm{~F}(15,480)=0.883, \mathrm{p}=0.583$, \\
& Placebo & $16.22 \pm 9.15$ & $14.94 \pm 9.07$ & $13.44 \pm 9.40$ & $14.67 \pm 9.94$ & $12.72 \pm 8.71$ & $12.78 \pm 9.37$ & eta $^{2}=0.027$ \\
CGI- & Folic acid & $17.56 \pm 9.91$ & $16.50 \pm 9.91$ & $16.28 \pm 9.14$ & $14.61 \pm 9.72$ & $13.78 \pm 9.54$ & $12.89 \pm 10.42$ & \\
& Placebo & $4.47 \pm 1.28$ & $4.33 \pm 1.19$ & $4.11 \pm 0.90$ & $3.89 \pm 0.90$ & $3.72 \pm 1.07$ & $3.28 \pm 1.23$ & \\
\hline
\end{tabular}

\section{Effect of the treatment on folate, homocysteine, and $B_{12}$ blood levels}

MANOVA was performed to investigate group (placebo vs. folic acid) differences in alteration $(\Delta)$ of the biochemical markers' levels as dependent variables (Serum folate, $\mathrm{B}_{12}$, homocysteine, and $\mathrm{RBC}$ folate). MANOVA showed that there were significant differrences between the groups $\left(\mathrm{F}_{(4,31)}=19.382, \mathrm{P}<0.0005\right.$, eta $_{\mathrm{p}}{ }^{2}=0.714$ ) in change of biochemical parameters' levels as expected. It can be seen in Table 2, further univariate examinations with Bonferroni adjustment (comparison-wise alpha $(0.05 / 4)=0.0125)$ showed that this differences between the groups originated from changes in mean serum folate $\left(\mathrm{F}_{(1,34)}=75.962, \quad \mathrm{P}<0.0005\right.$, eta $\left._{\mathrm{p}}{ }^{2}=0.691\right)$ and erythrocyte folate levels $\left(\mathrm{F}_{(1,34)}=36.137\right.$, $\mathrm{P}<0.0005$, eta $\left.{ }_{\mathrm{p}}{ }^{2}=0.515\right)$. However, no significant difference was found in changes in mean serum $B_{12}$ $\left(\mathrm{F}_{(1,34)}=0.108, \mathrm{P}=0.745\right.$, eta $\left.{ }_{\mathrm{p}}{ }^{2}=0.003\right)$ and homocysteine levels $\left(\mathrm{F}_{(1,34)}=4.115, \mathrm{P}=0.050\right.$, eta $\left._{\mathrm{p}}{ }^{2}=0.108\right)$ between placebo and folic acid groups.

\section{Association between treatment response and biochemical parameters}

Overall response rate to treatments was $38.9 \%$ $(n=14)$. At the end point, there was no significant differ- rence in response rate between placebo $(44.4 \%, \mathrm{n}=8)$ and folic acid $\left(33.3 \%, \mathrm{n}=6, \chi^{2}=0.117, \mathrm{df}=1, \mathrm{P}=0.732\right)$ in addition to fluoxetine groups. Further analysis was performed to compare whether responders different from non-responders in the levels of mentioned biochemical parameters. MANOVA showed that there was no association between response and the biochemical parameters' levels $\left(\mathrm{F}_{(4,31)}=0.481, \mathrm{P}=0.750\right.$, eta $\left.{ }_{\mathrm{p}}{ }^{2}=0.058\right)$. At the end of study, categorical assessments (low or not) of the biochemical parameters showed that none of the patients' erythrocyte folate or serum folate levels were low according to reference intervals no longer. But, 7 $(19.4 \%)$ patients still have low serum $B_{12}$ level, and 9 $(25.0 \%)$ patients' serum total homocysteine levels were higher than upper limits at the study's endpoint. $\mathrm{B}_{12}$ deficiency or high serum total homocysteine level was not associated with the treatment response (Fisher's exact test, $\mathrm{P}=0.681$ and $\mathrm{P}=0.712$ respectively).

\section{Secondary psychometric assessment tools}

Again, mixed model repeated measures ANOVA was performed to investigate group (placebo vs. folic acid) and gender differences, and group $\mathrm{x}$ gender interactions in psychometric assessment tools as dependent variables (HAM-D, HAM-A, CGI-S) collected over six measure- 
ments. Multivariate tests' results showed that neither significant main effect of the groups $\left(\mathrm{F}_{(15,480)}=0.883\right.$, $\mathrm{P}=0.583$, eta ${ }_{\mathrm{p}}^{2}=0.027$ ) nor main effect of gender $\left(\mathrm{F}_{(15,480)}=0.295, \mathrm{P}=0.996\right.$, eta $\left._{\mathrm{p}}{ }^{2}=0.009\right)$ or group $\mathrm{x}$ gender interaction $\left(\mathrm{F}_{(15,480)}=0.614 \mathrm{P}=0.864\right.$, eta $\left.{ }_{\mathrm{p}}{ }^{2}=0.019\right)$ in change of secondary psychometric scales' scores (Table 3 ). Repeated measures ANCOVA showed that $\Delta$ in the biochemical markers $\left(\Delta\right.$ folate $\mathrm{F}_{(15,465)}=1.103, \mathrm{P}=0.350$, eta $_{\mathrm{p}}{ }^{2}=0.034 ; \Delta$ erythrocyte folate $\mathrm{F}_{(15,465)}=0.671, \mathrm{P}=0.813$, eta ${ }_{\mathrm{p}}{ }^{2}=0.021 ; \Delta$ homocysteine $\mathrm{F}_{(15,465)}=0.268, \mathrm{P}=0.998$, eta $_{\mathrm{p}}{ }^{2}=0.009 ; \Delta \mathrm{B}_{12} \mathrm{~F}_{(15,465)}=0.320, \mathrm{P}=0.993$, eta $_{\mathrm{p}}{ }^{2}=0.010$ ) were not significantly associated with secondary psychometric scales' scores collected over six measurements.

\section{DISCUSSION}

To the best of our knowledge, there are no previous studies in the literature regarding folate in the treatment of OCD. But, the two studies merely exploring serum folate, $\mathrm{B}_{12}$ and homocysteine in OCD and found relationship between those substances and symptoms of OCD (Hermesh et al. 1988, Atmaca et al. 2005). In this trial, we observed similar improvement in symptoms of OCD between each of the two treatment arms (fluoxetine+placebo vs. fluoxetine+folic acid co-administration groups) with no significant superiority each other. Adding folic acid in fluoxetine had not significantly better than fluoxetine+placebo group on both efficacy measures (changes in Y-BOCS total scores and response rate) even after adjusting for sex. Many researches have been pointing out the beneficial effect of folic acid add on treatment in depression (Carney et al. 1990, Fava et al. 1997, Abou-Saleh \& Coppen 1989, Bottiglieri et al. 1992, Bottiglieri et al. 2000, Coppen et al. 1989, Coppen \& Bailey 2000, Papakostas et al. 2005, Papakostas et al. 2004, Papakostas et al. 2004, Wilkinson et al. 1994, Guaraldi et al. 1993, Di Palma et al. 1994, Alpert et al. 2002, Godfrey et al. 1990, Bottiglieri \& Hayland 1994), but we could not extend this to OCD. In the meanwhile, the findings of present study has not supported the previous study reported that change in RCF is closely tied to response to antidepressant treatment (Levitt et al. 1998). Despite a few previous cross sectional studies reporting lowered folate, $\mathrm{B}_{12}$ and increased homocysteine levels in OCD (Hermesh et al. 1988, Atmaca et al. 2005), none of our participants had a baseline lower serum folate than the normal range. The most reasonable explanation for this might be culturally or locally defined dietary habits influence the relationship between the folate statuses in different societies. For example in Chinese patients with depresssion had significantly lower serum folate than controls, but no subject in either group had low serum folate according to their normal range? Conversely, patients with depression significantly higher erythrocyte folate than control subjects (Lee et al. 2003). In a study examines associations between depression and folate status indicators in an ethnically diverse general US population sample aged 15-39 years found that subjects who met criteria for a lifetime diagnosis of major depression had folate concentrations in serum and RBCs, but not serum total homocysteine concentration, were lower than those of subjects who had never been depressed after adjustment for sociodemographic and biochemical factors (Morris et al. 2003). In this area, we can say that the traditional diets in western region of Turkey contain a high proportion of green vegetables and are hence rich in folate. This may explain why we could not find serum folate deficiency. Here, we should address the limitation that the dietary intakes of folic acid were not controlled in the study. Nevertheless, the present study's design limits us to discuss further on differences between healthy group and patients with OCD due to noninclusion of healthy comparison control group.

The biochemical mechanisms through which folate exerts an influence on neuropsychiatric status are suggested to be likely to involve the one-carbon cycle, a pathway essential to many transmethylation reactions within the CNS, including the metabolism of neuroactive substances such as the monoamine neurotransmitters and melatonin, as well as the formation of membrane phospholipids, and the synthesis, repair, and recombination of nucleic acids (Alpert \& Fava 1997, Fenech 2001, Young \& Ghadirian 1989). Concordant with the preclinical research, it is well known that serum folate, $\mathrm{B}_{12}$ and homocysteine are strongly associated with depressive disorders (Tiemeier et al. 2002), alcoholism (De La Vega et al. 2001) and Alzheimer's disease (Serot et al. 2001, Serot et al. 2005). We could not replicate that serum folate deficiency, which have been previously reported for wide range of psychiatric disorders, in OCD; however, some of the other disturbances (lowered erythrocyte folate level and or serum $\mathrm{B}_{12}$ level or increased serum total homocysteine) which are relevant to one carbon cycle were found. It is interesting to find disturbances in homocysteine and erythrocyte folate levels whereas normal serum folate level. An explanation for that is a defective gene of methylating enzyme 5, 10-methylenetetrahydrofolate reductase (MTHFR). Depressed patients are known to be at risk for MTHFR (C677T) polymorphism, which translates into lower serum levels of L-methylfolate and possibly lower CNS folate, and thus lower monoamine and increased homocysteine levels (Yang et al. 2008). Specific ethnic groups are at higher risk for the less functional forms of MTHFR. For example, the T/T genotype is present in as many as $10 \%$ of whites, and up to $22 \%$ of samples of Hispanic or Mediterranean populations (Arinami et al. 1997, Kelly et al. 2004). Although many studies including a meta analysis found an association between MTHFR polymorphism and depression (Arinami et al. 1997, Kelly et al. 2004, Hickie et al. 2001, Gilbody et al. 2007) one large $(n=6.806)$ population based cross sectional study examined the risk of anxiety, using a validated self-report questionnaire, and found no association between MTHFR gene polymorphism and anxiety disorders (Bjelland et al. 2003). Similarly, none of the newly admitted patients with 
anxiety disorders had lower serum $\mathrm{B}_{12}$ or folic acid levels which had been reported from Israel (Lerner et al. 2006). However, the small number of individuals in the study could possibly explain the negative results. Homocysteine levels are also particularly high in patients with schizophrenia, even in the absence of dietary deficiency in folate or vitamin $\mathrm{B}_{12}$ (Regland et al. 1995, Susser et al. 1998). The same is also true for $\mathrm{B}_{12}$ (Lindenbaum et al. 1988). Similarly, increased postprandial levels of homocysteine, but normal fasting levels in depressive patients, were proposed to indicate some enzymatic defect (Candito et al. 1997). In this point of view, it would be suggested that methylfolate might be chosen in the future research as active molecule for avoiding from confounding affect of MTHFR polymorphism. Because of both folic acid and dihydrofolate are not biologically active forms of folate, but are essentially pro-drugs, and must undergo enzymatic transformation to L-methylfolate in order to be used by cells, and unlike other forms of folate, L-methylfolate as bioactive derivate of folate readily crosses the bloodbrain barrier for use in the CNS. Additionally, it was previously shown that methylfolate significantly improved the outcome of depressed patients with definite or just borderline folate deficiency after additions of - to standard psychotropic treatment in a double-blind, placebo-controlled study (Godfrey et al. 1990). Later, lower serum levels of methylfolate have been reported among depressed subjects, although those levels were not related to severity of depression before treatment and values remained markedly low even after a good response to treatment (Wilkinson et al. 1994).

SSRI antidepressants are thought to work by stopping the reuptake of serotonin, thereby enhancing serotonin action within the synapse which results in a therapeutic efficacy in many psychiatric disorders. It seems that the efficacy of folate in psychiatric disorders, especially depression, can not be simplified as increasing the rate of serotonin synthesis. If this assumption was true, then, we might have found that folate had increased the response rate or fasten the response when we ignored the possible statistical insufficiency. Additionally, the present study demonstrated that metabolites relevant to one carbon cycle are not associated with the change in severity of OCD symptoms or treatment response to medication. Finally, limited statistical power because of the modest sample size in the present study $(\mathrm{N}=36)$ may have played a role in limiting the significance of some of the statistical comparisons conducted.

The readers should note as the limitations that the study has a relative small sample, not implemented a dietary restriction, and not used methylfolate the active metabolite of folate.

\section{CONCLUSIONS}

We observed similar improvement in symptoms of OCD between each of the two treatment arms (fluoxetine + placebo vs. fluoxetine + folic acid co-administra- tion groups) with no significant superiority each other. Adding folic acid in fluoxetine had not significantly better than fluoxetine+placebo group on both efficacy measures (changes in Y-BOCS total scores and response rate) even after adjusting for sex.

\section{Acknowledgements:}

This was an investigator-initiated study and partly supported by Lilly İlaç Ticaret A.Ş, Turkey, and I.E.Ulugay. Lilly Illaç Ticaret A.Ş. has afforded the biochemical kits, I.E. Ulugay has offered free drug (folic acid) and matching placebo pills used in the study.

\section{Conflict of interest:}

Dr. Ümit Tural have given independent lectures at educational activities sponsored by Astra Zeneca, Janssen and Abdi İbrahim, companies for which he received the honoraria were paid to the Department of Psychiatry, Medical Faculty, University of Kocaeli.

\section{Contribution of individual authors:}

Ümit Tural had the study conception, designed the study, performed statistical analyses and interpretation of data, drafting of the manuscript and critical revisions.

Aytül Çorapçıoğlu \& Şükriye Boşgelmez participated in collection and interpretation of data and drafting of the manuscript.

Gültürk Köroğlu \& Hatice Ünver had literature searches and drafting the manuscript.

Can Duman has involved the acquisition and interpretation of data.

Emin Önder made critical revisions, approval of the final version.

All authors made important intellectual content to the manuscript.

\section{References}

1. Abou-Saleh MT, Coppen A: The biology of folate in depression: implications for nutritional hypotheses of the psychoses. J Psychiatr Res 1986; 20:91-101

2. Abou-Saleh MT, Coppen A: Serum and red blood cell folate in depression. Acta Psychiatr Scand 1989;80:78-82

3. Akdemir A, Turkcapar MH, Orsel SD et al.: Reliability and validity of the Turkish version of the Hamilton Depression Rating Scale. Compr Psychiatry 2001; 42:161-165

4. Alpert JE, Fava M: Nutrition and depression: the role of folate. Nutr Rev 1997; 55:145-149

5. Alpert JE, Mischoulon D, Rubenstein GE et al.: Folinic acid (Leucovorin) as an adjunctive treatment for SSRIrefractory depression. Ann Clin Psych 2002; 14:33-38

6. Arinami T, Yamada N, Yamakawa-Kobayashi K et al.: Methylenetetrahydrofolate reductase variant and schizophrenia/depression. Am J Med Genet 1997; 74:526-528

7. Atmaca M, Tezcan E, Kuloglu M et al.: Serum folate and homocysteine levels in patients with obsessive-compulsive disorder. Psychiatry Clin Neurosci 2005; 59:616-620 
8. Baxter LR: Functional imaging of brain systems mediating obsessive-compulsive disorder. In: Charney DS, Nestler EJ, Bunny BS, eds. Neurobiology of Mental Illness. New York: Oxford University Press, 2001; 534-547

9. Bjelland I, Tell GS, Vollset SE et al.: Folate, vitamin B12, homocysteine, and the MTHFR $677 C$ - $>$ T polymorphism in anxiety and depression: the Hordaland Homocysteine Study. Arch Gen Psychiatry 2003; 60:618-626

10. Botez MI, Young SN, Bachevalier $J$ et al.: Folate deficiency and decreased brain 5-hydroxytryptamine synthesis in man and rat. Nature 1979; 278:182-183

11. Botez MI, Young SN, Bachevalier J et al.: Effect of folic acid and vitamin B12 deficiencies on 5-hydroxyindoleacetic acid in human cerebrospinal fluid. Ann Neurol 1982; 12:479-484

12. Bottiglieri T, Hyland $K$, Laundy $M$ et al.: Folate deficiency, biopterin and monoamine metabolism in depression. Psychol Med 1992; 22:871-876

13. Bottiglieri T, Hyland $\mathrm{K}$ : S-adenosylmethionine levels in psychiatric and neurological disorders: a review. Acta Neurol Scand 1994; 154(suppl):19-26

14. Bottiglieri T, Laundy M, Crellin R et al.: Homocysteine, folate, methylation, and monoamine metabolism in depression. J Neurol Neurosurg Psychiatry 2000; 69:228-232

15. Candito M, Aubin-Brunet V, Beaulieu F et al.: Increased postprandial homocysteinemia in a group of depressed patients. Amino Acids 1997; 12:315-321

16. Carney MW, Chary TK, Laundy $M$ et al.: Red cell folate concentrations in psychiatric patients. J Affect Disord 1990; 19:207-213

17. Coppen A, Swade C, Jones SA et al.: Depression and tetrahydrobiopterin: the folate connection. J Affect Disord 1989; 16:103-107

18. Coppen A, Bailey J: Enhancement of the antidepressant action of fluoxetine by folic acid: a randomised, placebo controlled trial. J Affect Disord 2000; 60:121-130

19. Coric V, Taskiran S, Pittenger $C$ et al.: Riluzole augmenttation in treatment-resistant obsessive-compulsive disorder: an open-label treatment. Biol Psychiatry 2005; 58:424-428

20. De la Vega MJ, Santolaria F, Gonzalez-Reimers $E$ et al.: High prevalence of hyperhomocysteinemia in chronic alcoholism: the importance of the thermolabile form of the enzyme methylenetetrahydrofolate reductase (MTHFR). Alcohol 2001; 25:59-67

21. Di Palma C, Urani R, Agricola $R$ et al.: Is methylfolate effective in relieving major depression in chronic alcoholics? A hypothesis of treatment. Curr Ther Res Clin Exp 1994; 55:559-568

22. Fava M, Borus JS, Alpert JE et al.: Folate, vitamin $B_{12}$, and homocysteine in major depressive disorder. Am J Psychiatry 1997; 154:426-428

23. Fenech M: The role of folic acid and Vitamin $B 12$ in genomic stability of human cells. Mutat Res 2001; 475:57-67

24. Gilbody S, Lewis S, Lightfoot T: Methylenetetrahydrofolate reductase (MTHFR) genetic polymorphisms and psychiatric disorders: a HuGE review. Am J Epidemiol 2007; 165:1-13

25. Godfrey PS, Toone BK, Carney MW et al.: Enhancement of recovery from psychiatric illness by methylfolate. Lancet 1990; 336:392-395

26. Goodman W, Price LH, Steven A et al.: Yale-Brown obsessive compulsive scale. I. Development, use, and reliability. Arch Gen Psychiatry 1989; 46:1006-1011
27. Guaraldi GP, Fava M, Mazzi F et al.: An open trial of methyltetrahydrofolate in elderly depressed patients. Ann Clin Psychiatry 1993; 5:101-105

28. Guy W: Early Clinical Drug Evaluation until Assessment Manual for Psychopharmacology. Washington DC: US Department of Health, Education and Welfare, 1976; 76-338

29. Hamilton M: Development of a rating scale for primary depressive illness. Br J Soc Clin Psychol 1967; 6:278-296

30. Hamilton M: Diagnosis and rating of anxiety. $\mathrm{Br} J$ Psychiatry. 1969; 3:76-79.

31. Hamon CG, Blair JA, Barford PA: The effect of tetrahydrofolate on tetrahydrobiopterin metabolism. J Ment Defic Res 1986; 30:179-183

32. Hermesh H, Weizman A, Shahar A et al.: Vitamin B12 and folic acid serum levels in obsessive compulsive disorder. Acta Psychiatr Scand 1988; 78:8-10

33. Hickie I, Scott E, Naismith S et al.: Late-onset depression: genetic, vascular and clinical contributions. Psychol Med 2001; 31:1403-1412

34. Jenike MA: Clinical practice. Obsessive-compulsive disorder. N Engl J Med 2004; 350:259-265

35. Karamustafalıoğlu OK, Üçlşı AM, Ulusoy $M$ et al.: Validity and reliability study of Yale-Brown ObsessionCompulsion Scale. Poster presented at $29^{\text {th }}$ Congress of National Psychiatry Procedings Book. 1993:86 [Turkish]

36. Kelly CB, McDonnell AP, Johnston $T G$ et al.: The MTHFR C677T polymorphism is associated with depressive episodes inpatients from Northern Ireland. $J$ Psychopharmacol 2004; 18:567-571

37. Lee J, Kim BH, Kim E et al.: Higher serotonin transporter availability in early-onset obsessive-compulsive disorder patients undergoing escitalopram treatment: $A\left[{ }^{11} C\right] D A S B$ PET study. Hum Psychopharmacol 2018; 33:e2642

38. Lee S, Wing YK, Fong S: A controlled study of folate levels in Chinese inpatients with major depression in Hong Kong. J Affect Disord 1998; 49:73-77

39. Lerner V, Kanevsky M, Dwolatzky $T$ et al.: Vitamin B12 and folate serum levels in newly admitted psychiatric patients. Clinical Nutrition 2006; 25:60-67

40. Levitt AJ, Wesson VA, Joffe RT: Impact of suppression of thyroxine on folate status during acute antidepressant therapy. Psychiatry Res 1998; 79:123-129

41. Lindenbaum J, Healton EB, Savage DG et al.: Neuropsychiatric disorders caused by cobalamin deficiency in the absence of anemia or macrocytosis. $N$ Engl $J$ Med 1988; 318:1720-1728

42. Martenyi F, Dossenbach M, Mraz K et al.: Gender differences in the efficacy of fluoxetine and maprotiline in depressed patients: a double-blind trial of antidepressants with serotonergic or norepinephrinergic reuptake inhibition profile. Eur Neuropsychopharmacol 2001; 11:227-232

43. Morris MS, Fava M, Jacques PF et al.: Depression and folate status in the US Population. Psychother Psychosom 2003; 72:80-87

44. Papakostas GI, Petersen T, Mischoulon D et al.: Serum folate, vitamin B12, and homocysteine in major depressive disorder, Part 1: predictors of clinical response in fluoxetine-resistant depression. J Clin Psychiatry 2004; 65:1090-1095

45. Papakostas GI, Petersen T, Mischoulon D et al.: Serum folate, vitamin B12, and homocysteine in major depressive disorder, Part 2: predictors of relapse during the continuation phase of pharmacotherapy. J Clin Psychiatry 2004; 65:1096-1098 
46. Papakostas GI, Petersen T, Lebowitz BD et al.: The relationship between serum folate, vitamin B12, and homocysteine levels in major depressive disorder and the timing of improvement with fluoxetine. Int $J$ Neuropsychopharmacol 2005; 8:523-528

47. Regland B, Johansson BV, Grenfeldt B et al.: Homocysteinemia is a common feature of schizophrenia. $J$ Neural Transm Gen Sect 1995; 100:165-169

48. Ruck A, Kramer S, Metz J, Brennan M: Methyltetrahydrofolate is a potent and selective agonist for kainic acid receptors. Nature 1980; 287: 852

49. Serot JM, Christmann D, Dubost $T$ et al.: CSF-folate levels are decreased in late-onset AD patients. J Neural Transm 2001; 108:93-99

50. Serot JM, Barbe F, Arning E et al.: Homocysteine and methylmalonic acid concentrations in cerebrospinal fluid: relation with age and Alzheimer's disease. J Neurol Neurosurg Psychiatry 2005; 76:1585-1587

51. Sinopoli VM, Burton CL, Kronenberg $S$ et al: A review of the role of serotonin system genes in obsessive-compulsive disorder. Neurosci Biobehav Rev 2017; 80:372-381

52. Susser E, Brown AS, Klonowski E et al.: Schizophrenia and impaired homocysteine metabolism: a possible association. Biol Psychiatry 1998; 44:141-143

53. Tiemeier H, van Tuijl HR, Hofman A et al.: Vitamin B12, folate, and homocysteine in depression: the Rotterdam Study. Am J Psychiatry 2002; 159:2099-2101
54. Tolmunen T, Hintikka J, Ruusunen A et al.: Dietary folate and the risk of depression in Finnish middle-aged men. A prospective follow-up study. Psychother Psychosom 2004; 73:334-339

55. Van Praag HM: Depression, suicide and the metabolism of serotonin in the brain. J Affect Disord 1982; 4:275290

56. Westenberg H, Fineberg NA, Denys D: Neurobiology of Obsessive-Compulsive Disorder: Serotonin and Beyond. CNS Spectr 2007; 12(Suppl 3):14-27

57. Wilkinson AM, Anderson DN, Abou-Saleh MT et al.: 5Methyltetrahydrofolate level in the serum of depressed subjects and its relationship to the outcome of ECT. $J$ Affect Disord 1994; 32:163-168

58. Yang QH, Botto LD, Gallagher $M$ et al.: Prevalence and effects of gene-gene and gene-nutrient interactions on serum folate and serum total homocysteine concentrations in the US: findings from the third national health and nutrition examination survey DNA bank. Am J Clin Nutr 2008; 88:232-246

59. Yazıcı MK, Demir B, Tanriverdi $N$ et al.: Validity and inter-rater reliability of Hamilton Anxiety Rating Scale. Turk Psikiyatri Derg 1998; 9:114-117 [Turkish]

60. Young SN, Ghadirian AM: Folic acid and psychopathology. Prog Neuropsychopharmacol Biol Psychiatry 1989; 1 3:841-863

Correspondence:

Hatice Ünver, $M D$

Department of Child and Adolescent Psychiatry,

Medical Faculty at the University of Marmara

Istanbul, Turkey

E-mail:drhaticeunver@gmail.com 